\title{
Finite Element Analysis of Wheel Rim Using Abaqus Software
}

\author{
*Bimal Bastin, *Adars S, *Akshay Madhu, *Arun Krishnan, *Betson Jose, \\ **Praveen Raj \\ *(UG Scholars, Department of Mechanical Engineering, Jyothi Engineering College, Thrissur, India) \\ ** (Assistant Professor, Department of Mechanical Engineering, Jyothi Engineering College, Thrissur, India)
}

\begin{abstract}
The rim is the "outer edge of a wheel, holding the tire". It makes up the outer circular design of the wheel on which the inside edge of the tire is mounted on vehicles such as automobiles. A standard automotive steel wheel rim is made from a rectangular sheet metal. Design is an important industrial activity which influences the quality of the product being produced. The wheel rim is modeled by using modeling software SOLIDWORKS . Later this modal is imported to ABAQUS for analysis. Static load analysis has been done by applying a pressure of $5 \mathrm{~N} / \mathrm{mm}^{2}$. The materials taken for analysis are steel alloy, Aluminium, Magnesium, and Forged Steel. The displacement occurred to the rim is noted after applying the static load to different materials and maximum principal stresses were also noted
\end{abstract}

Keywords: Design, modeling software, A BAQUS, analysis, SOLIDW ORKS, static load, principal stresses.

\section{INTRODUCTION}

The original of the wheel were the round slices of a $\log$ and it was gradually re-inforced and used in this form for centuries on both carts and wagons. This solid disc changed to a design having several spokes radially arranged to support the outer part of the wheel keeping it equidistant from the wheel centre. The steel disk wheel and the light alloy wheel are the most typical installation. The method of manufacturing the light alloy wheel, which has become popular in recent years, is explained here. The manufacturing method for the light alloy wheel is classified into two. They are cast metal or the forged manufacturing methods. The alu minum alloy wheel is manufactured both ways, and the casting manufacturing method is used as for the magnesium alloy wheel.

In this work static analysis of wheel rim made with materials like alluminium alloy, steel alloy, forged steel and magnesium alloy is done. The finite element method is a powerful tool or the numerical procedure to obtain solutions to many of the problems encountered in engineering analysis. In this method of analysis, a complex region defining a continuum is discretized into simple geometric shapes called finite elements. The domain over which the analysis is studied is divided into a number of finite elements. The material properties and the governing relationship are considered over these elements and expressed in terms of unknown values at element corner. In the static analysis of wheel rim constraints will be applied on the hub.

In this work the wheel rim is modeled in solidworks software and the model is imported to abaqus software for static analysis.
II. MODELING

As told before, the wheel rim was modeled in solidworks software. The model of the wheel rim is shown below:
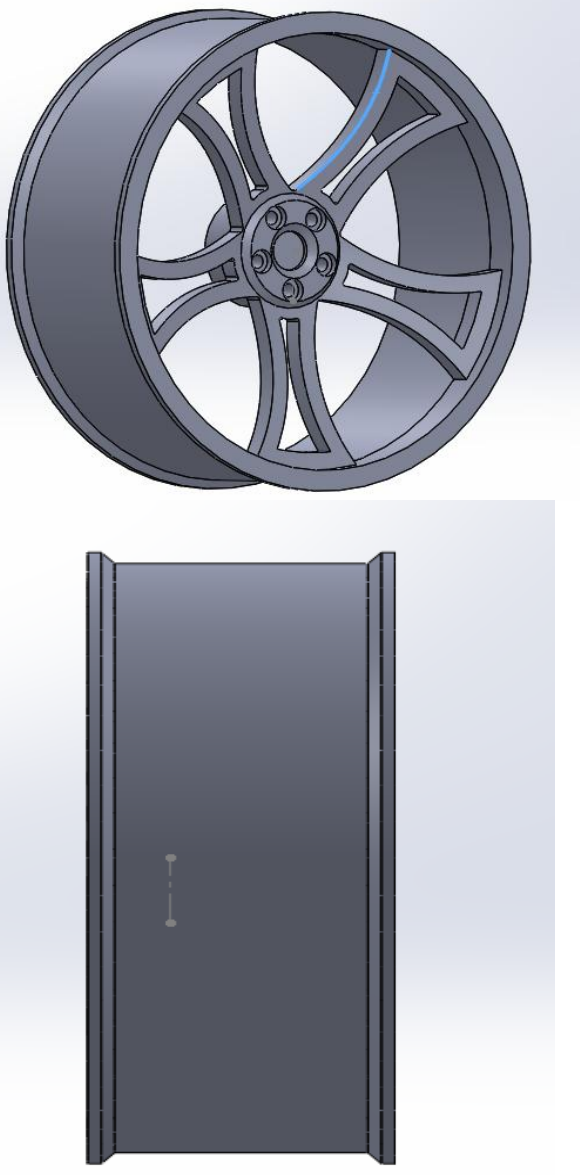

SIDE VIEW 


\section{ANALYSIS}

Analysis is done using abaqus software. ABAQUS is a high-performance fin ite element preand postprocessor for popular finite element solvers - allowing engineers to analyze product design performance in a highly interactive and visual environment. The steps involved are:

\section{a. Meshing the finished model}

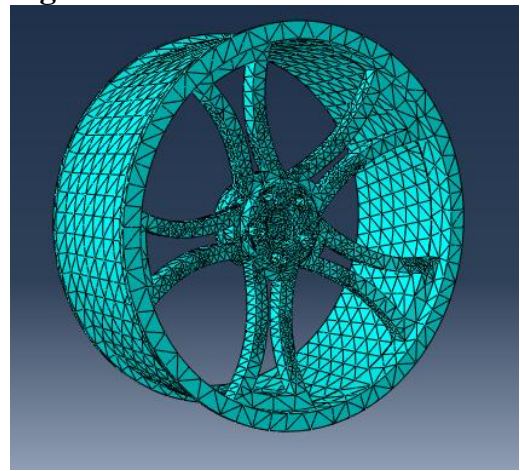

b. B oundary conditions and Pressuring.

A pressure of $5 \mathrm{~N} / \mathrm{mm}^{2}$ is applied on the circu mference by encastring the hub hole.

Displacements:

$\mathrm{U} 1=\mathrm{U} 2=\mathrm{U} 3=\mathrm{UR} 1=\mathrm{UR} 2=\mathrm{UR} 3=0$

\section{c. Dis placement pl ots:}

- Steel alloy
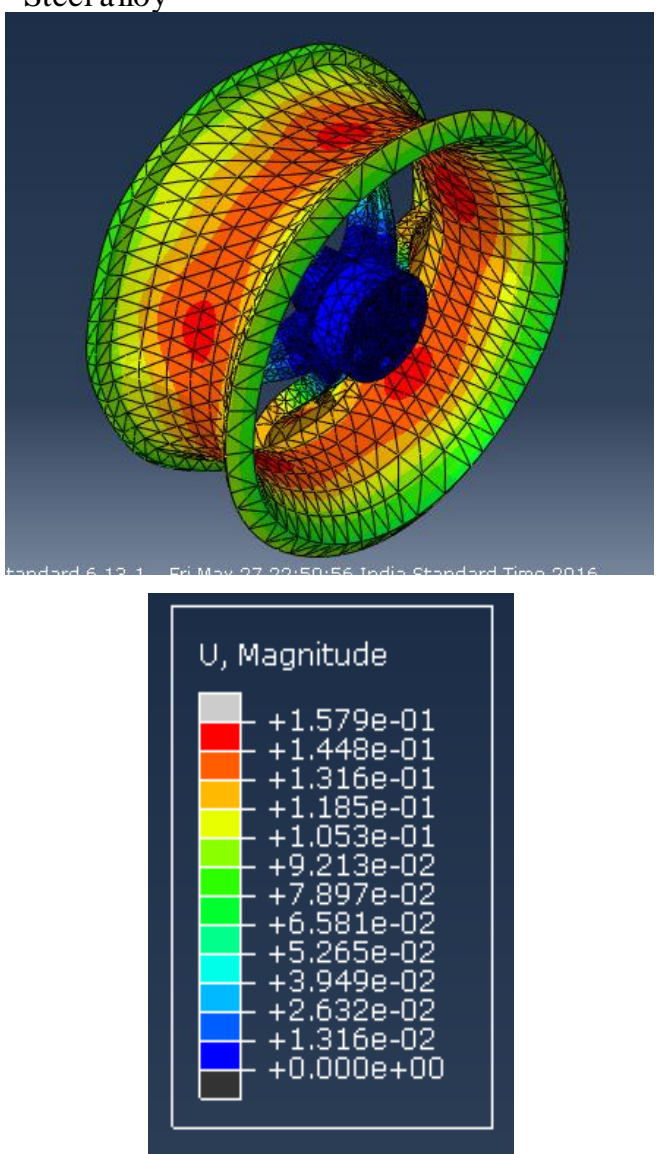

- Aluminium alloy
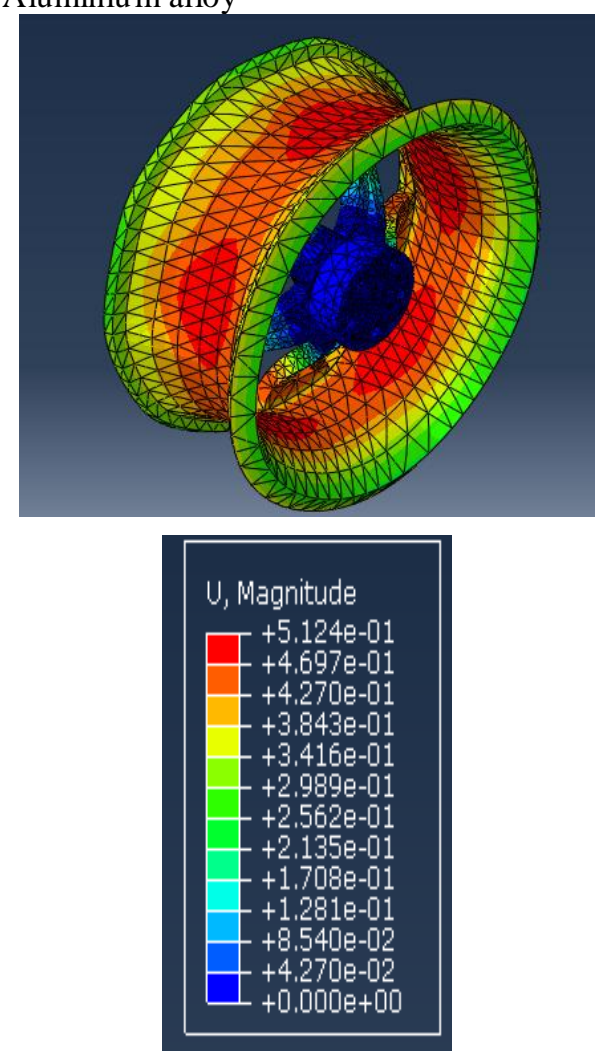

- Magnesiumalloy
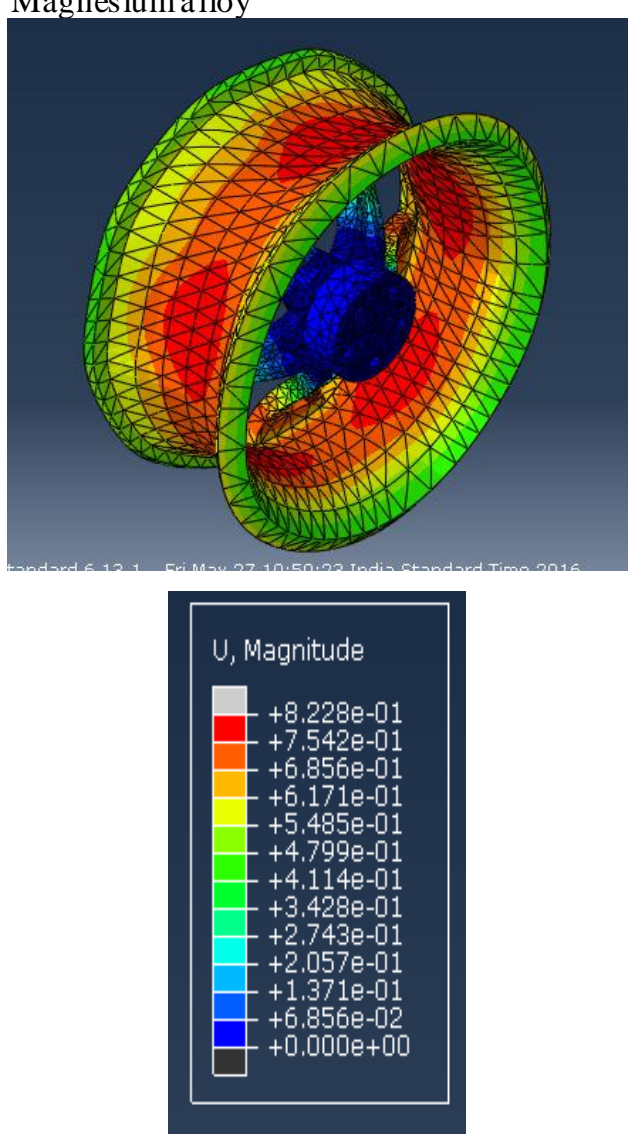

ISSN : 2248-9622, Vol. 7, Issue 2, ( Part -1) February 2017, pp.31-34

- $\quad$ Forged steel
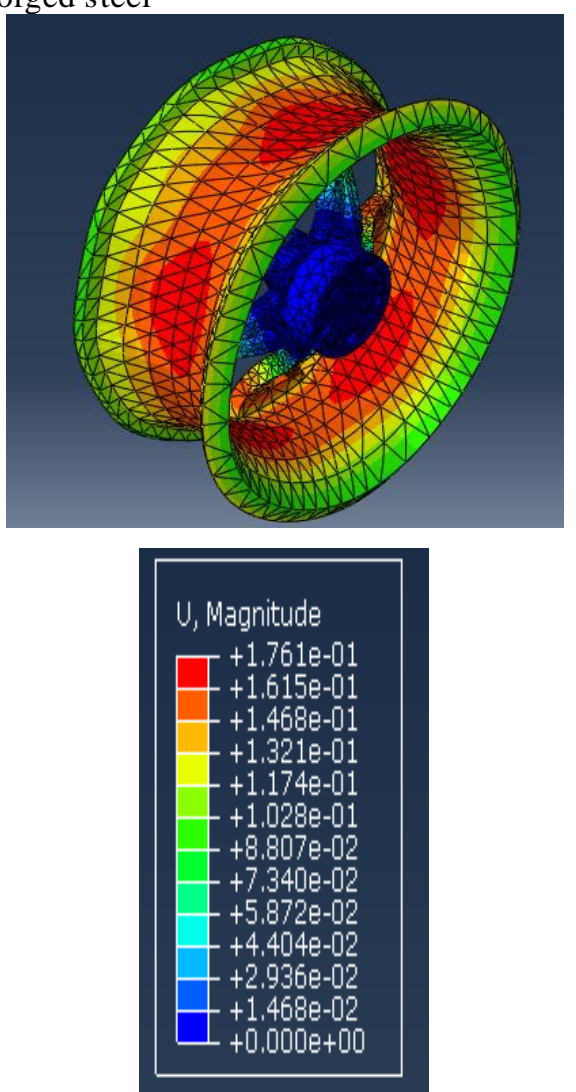

d. Max Principal Stress pl ots

- Steel alloy
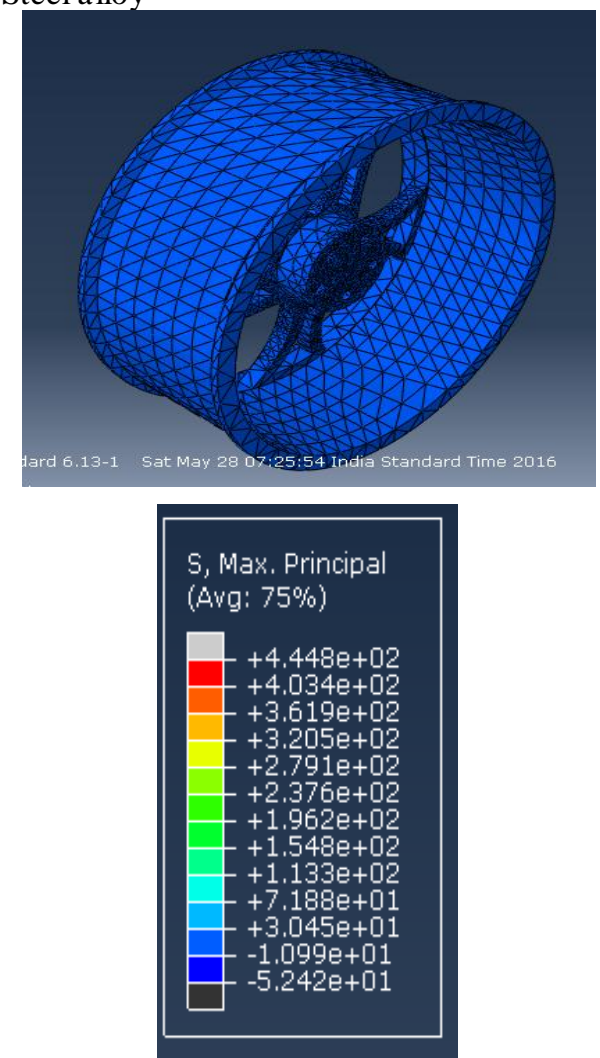

- Aluminium alloy
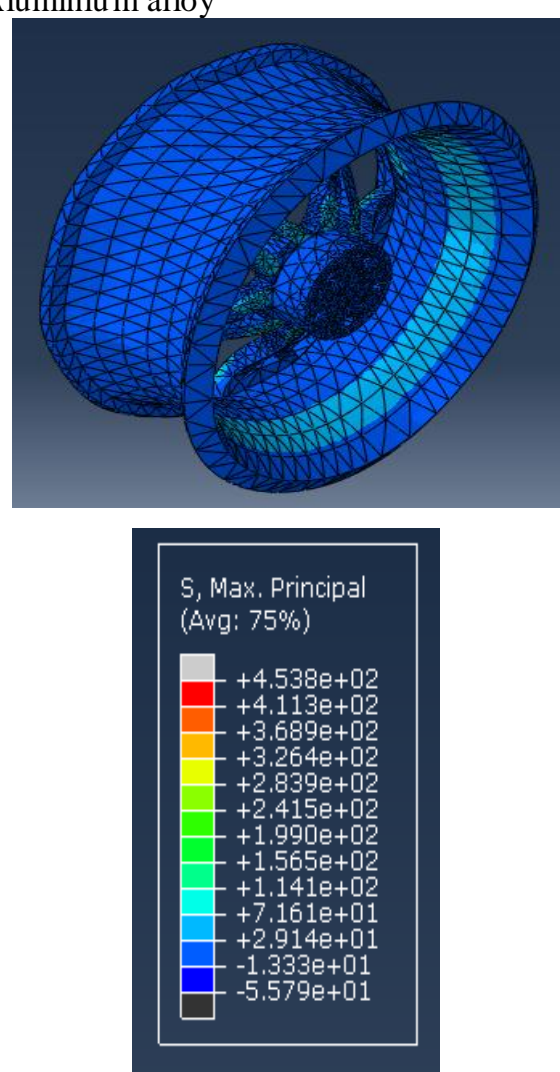

- Magnesium alloy
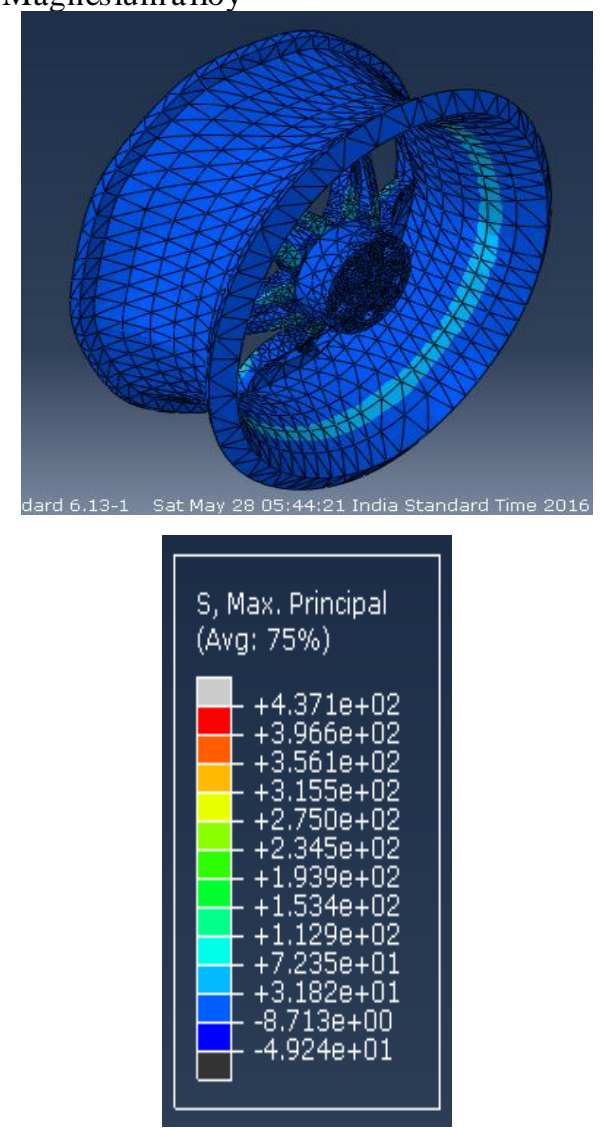
- $\quad$ Forged steel
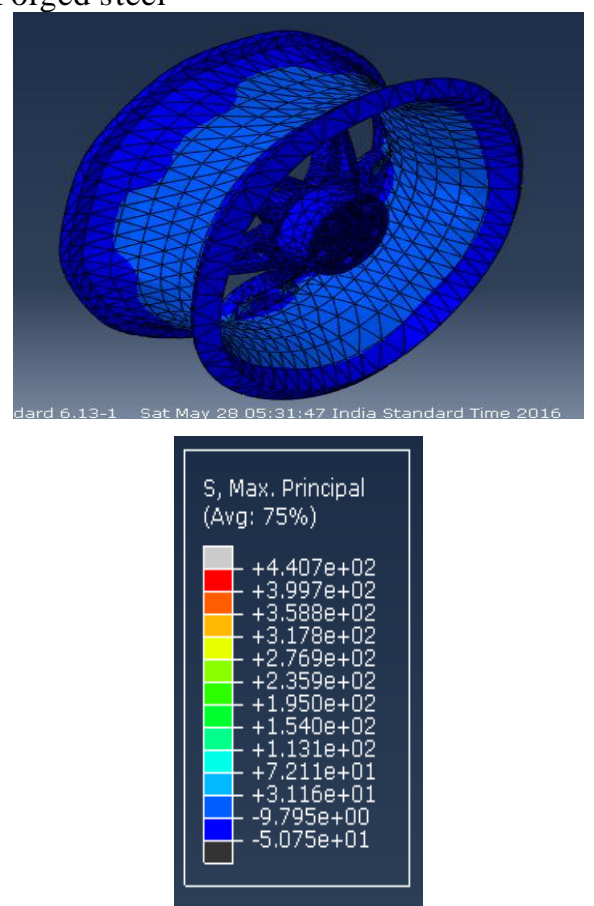

\section{RESULTS AND DISCUSSIONS}

\section{Material properties}

*Steel alloy:

Young's modulus $(\mathrm{E})=2.34 * 10^{5} \mathrm{~N} / \mathrm{mm}^{2}$

Yield stres $\mathrm{s}=240 \mathrm{~N} / \mathrm{mm}^{2}$

Density $=7800 \mathrm{~kg} / \mathrm{m}^{3}$

*Aluminum alloy:

Young's modulus $(\mathrm{E})=72000 \mathrm{~N} / \mathrm{mm}^{2}$

Yield stress $=160 \mathrm{~N} / \mathrm{mm}^{2}$

Density $=2800 \mathrm{~kg} / \mathrm{m}^{3}$

*Magnesium alloy:

Young's modulus $(\mathrm{E})=45000 \mathrm{~N} / \mathrm{mm}^{2}$

Yield stress $=130 \mathrm{~N} / \mathrm{mm}^{2}$

Density $=1800 \mathrm{~kg} / \mathrm{m}^{3}$

*Forged steel:

Young's modulus $(\mathrm{E})=210000 \mathrm{~N} / \mathrm{mm}^{2}$

Yield stress $=220 \mathrm{~N} / \mathrm{mm}^{2}$

Density $=7600 \mathrm{~kg} / \mathrm{m}^{3}$

Results obtained from software:

Steel alloy:-

Displace ment $=0.1579 \mathrm{~mm}$

Maximu $\mathrm{m}$ Principal Stress $=71.88 \mathrm{Mpa}$

Aluminu malloy:-

Displace ment $=0.5124 \mathrm{~mm}$

Maximu m Principal Stress $=71.61 \mathrm{Mpa}$

Magnesium alloy:-

Displace ment $=0.8228 \mathrm{~mm}$

Maximu m Principal Stress =72.35 Mpa.

Forged steel:-

Dis place ment $=0.1761 \mathrm{~mm}$
Maximu $\mathrm{m}$ Principal Stress $=72.11 \mathrm{Mpa}$

\section{CONCLUSION}

1) The Maximum Principal Stress developed in steel alloy during static analysis is $71.88 \mathrm{~N} / \mathrm{mm}^{2}$ at pressure $5 \mathrm{~N} / \mathrm{mm}^{2}$ and the displacement occurred is $0.1579 \mathrm{~mm}$

2) The Maximum Principal Stress developed in aluminum alloy during static analysis is 71.61 $\mathrm{N} / \mathrm{mm}^{2}$ at pressure $5 \mathrm{~N} / \mathrm{mm}^{2}$ and the displacement occurred is $0.512 \mathrm{~mm}$

3) The Maximum Principal Stress developed in Magnesium alloy during static analysis is 72.35 $\mathrm{N} / \mathrm{mm}^{2}$ at pressure $5 \mathrm{~N} / \mathrm{mm}^{2}$ and the displacement occurred is 0.8228

4) The Maximum Principal Stress developed in Forged steel during static analysis is 72.11 $\mathrm{N} / \mathrm{mm}^{2}$ at pressure $5 \mathrm{~N} / \mathrm{mm}^{2}$ and the displacement occurred is 0.1761

From results we can make out, in steel alloy the displacement occurred is smaller than Aluminium, Magnesium and Forged steel. Hence Steel alloy is more feasible to use than aluminum. Hence steel alloy have more life and durability compared to alu minu m.

\section{REFERENCES}

[1]. P. Meghashyam “ Design and Analysis of Wheel Rim using CATIA \& ANSYS“ international journal of application or innovation in engineering management, Volume 2, Issue 8 , August 2013.

[2]. Liangmo Wang* - Yufa Chen - Chenzhi Wang - Qingzheng Wang " the fatigue analysis of aluminium wheel rim" Strojniški vestnik - Journal of Mechanical Engineering 57(2011)1, 31-39-jme.2009. 046.

[3]. International Journal of Engineering Research \& Technology (IJERT) Vol. 3 Issue1 1, January - 2014, ISSN: 2278-0181 Modeling and Fatique Analysis of Auto-motive Wheel Rim.

[4]. Sunil N. Yadav, "Modelling and Analysis of Camber Angle on Fatigue Life of Wheel Rim of Passenger Car by Using Radial Fatigue Testing“, International Journal of Engineering Science and Innovative Technology (IJESIT) Volume 2,Issue 5, September 2013.

[5]. International Journal of Engineering Research \& Technology (IJERT) ISSN: 2278-0181, Volume 1 Issue, ISSN: 2277 8128, Stress Analysis Of Wheel Rim, Dr. Suwarna. 